\title{
FENOLOGIA DA FLORAÇÃO DA NOGUEIRA MACADÂMIA (Macadamia integrifolia Maiden \& Betche) NAS CONDIÇÕES CLIMÁTICAS DE JABOTICABAL, SÃO PAULO, BRASIL ${ }^{1}$
}

\author{
CÉLIO KERSUL SACRAMENTO² \& FERNANDO MENDES PEREIRA ${ }^{3}$
}

\begin{abstract}
RESUMO - Com o objetivo de conhecer a fenologia da floração da nogueira macadâmia, foram efetuadas observações, durante o período de maio de 1993 a outubro de 1995, em plantas do pomar da FCAV-UNESP, Jaboticabal, São Paulo, Brasil (latitude $21^{\circ} 15^{\prime}$ S, longitude $48^{\circ} 18^{\prime}$ W). Foram utilizadas plantas de 6 anos de idade, das cultivares IAC 5-10 e IAC 8-17, selecionadas no Brasil. Verificou-se que o período de intumescimento das gemas florais ocorreu a partir de maio. As gemas florais são mistas e localizam-se principalmente em ramos finos $(0,2$ a $0,7 \mathrm{~cm})$. Das três gemas existentes na axila foliar, a gema superior e a mediana geralmente originam inflorescências. O período ocorrido entre o início de crescimento da gema floral e a antese foi de 48 a 55 dias ou 330 a 350 graus-dia (temperatura-base $=12,8^{\circ} \mathrm{C}$ ). A inflorescência e a flor + pedicelo apresentaram um padrão de crescimento do tipo sigmoidal simples. O período de flores em antese concentrou-se entre meados de agosto e meados de setembro.
\end{abstract}

Termos para indexação: fisiologia, cultivar, graus-dia, crescimento

\section{FLOWERING PHENOLOGY OF MACADAMIA NUT TREE (Macadâmia integrifolia Maiden \& Betche) IN THE CLIMATIC CONDITIONS OF JABOTICABAL, SÃO PAULO, BRAZIL}

ABSTRACT - Studies about macadâmia flowering were carried under conditions of Jaboticabal, State of São Paulo, Brazil (latitude $21^{\circ} 15^{\prime}$ S, longitude $48^{\circ} 18^{\prime} \mathrm{W}$ ) from May 1993 to October 1995 using six years old plants of cultivar IAC 5-10 and IAC 8-17 selected by Instituto Agronômico de Campinas (IAC). There are three buds in the axis leaf but only on the upper and median form inflorescences. It was observed that floral buds born principally on thin branches ( diameter between 0.2 and $0.7 \mathrm{~cm}$ ) and in a period of 48 and 55 days or 330 and 350 degree days (base temperature $=12.8^{\circ} \mathrm{C}$ ) from initial buds to anthesis. Inflorescence and flower + pedicel presented sigmoid development. Initial period of flowering (white buds) occurred during May and anthesis occurred principally from August to September.

Index terms: physiology, cultivar, degree day, development

\section{INTRODUÇÃO}

A nogueira macadâmia (Macadamia integrifolia Maiden \& Betche) é uma árvore da família Proteaceae cuja noz é considerada a mais saborosa entre as nozes comercializadas no mundo. Originária da Austrália, a nogueira macadâmia foi introduzida no Havaí em 1878, onde ocupa uma área de aproximadamente 10.000 ha, correspondendo a $70 \%$ da produção mundial de nozes macadâmia (Bittenbender \& McGregor, 1991). No Brasil, foi introduzida em 1931, mas a expansão aconteceu a partir da década de 80, nos Estados de São Paulo, Bahia, Espírito Santo, Rio de Janeiro e Minas Gerais (Sacramento, 1991).

Em se tratando de uma cultura recente no Brasil, as informações disponíveis sobre a nogueira macadâmia e as tecnologias recomendadas para o seu cultivo têm sido extrapoladas e adaptadas de pesquisas efetuadas para as condições edafoclimáticas do Havaí e da Austrália.

No Havaí, a antese ocorre de novembro a maio com picos de floração entre janeiro e março (Nagao et al., 1988), enquanto nas condições da Costa Rica a floração de macadâmia se estende de novembro a fevereiro e a colheita vai geralmente de maio a dezembro (Sequeira \& Aste, 1984).

Moncur et al. (1985) estudaram a floração de macadâmia nas condições da Austrália e verificaram que a iniciação floral ocorreu durante o mês de maio com temperaturas mínimas entre 11 e $15^{\circ} \mathrm{C}$ seguido por um período de dormência de 50 a 96 dias.

Apesar de ser originária de clima de floresta tropical, a nogueira macadâmia desenvolve-se melhor em clima subtropical. Segundo Stephenson (1993), a iniciação floral pode ocorrer sob uma ampla ordem de condições no campo e as gemas florais permanecem dormentes por um período variável (50 a 96 dias). A dormência terminou quando houve aumento da temperatura após alguma chuva. Quando as condições são inadequadamente quentes, a floração de outono ocorre em adição à principal floração na primavera. A quebra da dormência da gema floral foi mais cedo em locais mais frios da Austrália.

$\mathrm{O}$ objetivo deste trabalho foi estudar os aspectos relativos à floração em duas cultivares de nogueira macadâmia nas condições de Jaboticabal, Estado de São Paulo.

\section{MATERIALEMÉTODOS}

Os ensaios foram realizados no pomar da Faculdade de Ciências Agrárias e Veterinárias, Universidade Estadual Paulista (FCAVUNESP), Câmpus de Jaboticabal, cujas coordenadas geográficas são latitude $21^{\circ} 17^{\prime} \mathrm{S}$, longitude $48^{\circ} 18^{\prime} \mathrm{W}$, altitude $590 \mathrm{~m}$. O clima da região segundo a classificação de Köeppen é do tipo Cwa, subtropical, relativamente seco no inverno, com chuvas de verão, apresentando temperatura média anual de $22^{\circ} \mathrm{C}$ e precipitação de $1552 \mathrm{~mm}$. O solo é classificado como latossolo vermelho-escuro.

Foram utilizadas as cultivares: IAC 5-10 e 8-17 (cultivares selecionadas pelo Instituto Agronômico de Campinas, oriundas de polinização aberta das cultivares havaianas Kakea e Waialua, respectivamente). As árvores, propagadas por estaquia herbácea, foram plantadas em março de 1987, no espaçamento $11 \mathrm{~m}$ x $6 \mathrm{~m}$.

A determinação do período de iniciação floral e crescimento de inflorescências foi efetuada através de observações semanais, no período de abril a agosto, nos anos 1993 a 1995. As observações foram efetuadas em ramos das partes interna e externa da planta. A iniciação floral foi considerada quando havia gemas intumescidas de coloração branca e o início de crescimento quando as mesmas apresentavam cerca de 2,5 mm de comprimento.

Para a determinação do período de abertura de flores, foram marcados, a partir de junho de 1995, 30 ramos em cada uma de 3 árvores da cultivar IAC 5-10 e 4 árvores da cultivar IAC 8-17. Os ramos marcados apresentavam gemas florais intumescidas e inflorescências em crescimento. Semanalmente, foram contadas as inflorescências com mais de $50 \%$ de flores em fase de pré-antese (estilete curvo) ou antese e, após o término do período de floração, foi determinada a média semanal de inflorescências com flores abertas por árvore em cada cultivar e os dados transformados em percentagem.

Para a determinação do número de dias e graus-dia entre o

\footnotetext{
${ }^{1}$ (Trabalho 011/2002). Recebido: 01/02/2002. Aceito para publicação:09/04/2003.

${ }^{2}$ Professor Adjunto do Depto de Ciências Agrárias e Ambientais da Universidade Estadual Santa Cruz, Km 16 Rod. Ilhéus-Itabuna, Ba 45.650.000 kersul@uesc.br.

${ }^{3}$ Professor Doutor Voluntário do Depto de Produção Vegetal-FCAV-UNESP Rod. Prof. Paulo Donato Castellane, km 5, CEP 14.870.000, Jaboticabal, SP.
} 
início de inflorescência e antese, foram marcadas, em junho de 1994 e junho de 1995, em árvores das cultivares IAC 5-10 e IAC 8-17, cerca de 10 a 20 gemas florais.

As inflorescências foram consideradas em início de crescimento quando apresentavam comprimento de $2,5 \mathrm{~mm}$ e final quando $50 \%$ das flores se apresentam em antese. O período decorrido entre as fases inicial e final foi convertido em graus-dia, utilizando-se, como temperatura-base para a macadâmia, do valor de $12,8^{\circ} \mathrm{C}$, conforme sugestão de Allan (1994). Em 1995, foram mensurados, semanalmente, os comprimentos das inflorescências e das flores + pedicelos dos ramos marcados.

\section{RESULTADOS E DISCUSSÃO}

Observou-se, que nas nogueiras macadâmia, a maioria das inflorescências ocorre em ramos maduros (com mais de um ano) com diâmetro entre 2 a $7 \mathrm{~mm}$. Esses ramos, originários de gemas axilares, desenvolvem-se pouco em virtude da competição com o ramo principal originário, na maioria das vezes, da gema apical.

As gemas vegetativas existentes na axila das folhas, e alguns casos também as gemas apicais, sofrem diferenciação e transformam-se em gemas florais. A diferenciação é caracterizada por um intumescimento das gemas seguido por um estágio em que as mesmas adquirem uma coloração branca, com cerca de $2 \mathrm{~mm}$ de comprimento, permanecendo dormentes neste estado por períodos variáveis, podendo até mesmo não evoluírem para inflorescências.

Das três gemas existentes na axila foliar, geralmente a gema superior e a mediana diferenciam-se em gema floral, fato que ocorre com menor freqüência na gema inferior. Desse modo, em cada nó, é possível a ocorrência de 1 até 9 inflorescências.

De acordo com Meyer (1965), as primeiras fases da transformação de um meristema vegetativo em floral são invisíveis alterações fisiológicas que originam, nas células meristemáticas, condições metabólicas que modificam completamente o tipo de diferenciação do meristema. Acrescenta, ainda, que o período de tempo em que um dado meristema apical permanece no estado vegetativo antes de transformar-se num meristema floral, difere muito de uma espécie vegetal para outra e, numa dada planta, de um meristema para outro, sendo condicionado em parte por fatores genéticos e, em parte, por fatores ambientais. Em algumas espécies, o meristema transforma-se num primórdio floral a partir do qual se desenvolve a inflorescência.

Nas observações efetuadas durante o período de maio de 1993 a outubro de 1995, verificou-se que o período de intumescimento das gemas florais brancas ocorreu a partir de meados do mês de maio, nos anos de 1993 a 1995, com maior incidência a partir de meados do mês de maio, nos anos de 1993 a 1995, com maior incidência a partir do início do mês de junho (Tabela 1).

TABELA 1- Estágios de floração em nogueiras macadâmia plantadas no pomar da FCAV-UNESP, de 1993 a 1995.

\begin{tabular}{lcccccc}
\hline Estágios de floração & \multicolumn{2}{c}{1993} & \multicolumn{2}{c}{1994} & \multicolumn{2}{c}{1995} \\
& \multicolumn{2}{c}{ Datas } & \multicolumn{2}{c}{ Datas } & \multicolumn{2}{c}{ Datas } \\
\hline $\begin{array}{l}\text { Gemas intumescidas } \\
\text { brancas }\end{array}$ & $20-5$ & s/observ. & $12-5$ & $17-6$ & $22-5$ & s/observ. \\
$\begin{array}{l}\text { Crescimento de } \\
\text { inflorescências }\end{array}$ & $9-6$ & $15-8$ & $18-5$ & $12-8$ & $22-6$ & $30-7$ \\
Flores em antese & $18-8$ & $10-9$ & $16-8$ & $7-9$ & $9-8$ & $23-8$ \\
\hline
\end{tabular}

A fase de crescimento de inflorescências variou entre os anos, estendendo-se de 9 de junho a 15 de agosto em 1993; de 18 de maio a 12 de agosto, em 1994, e de 22 de junho a 30 de julho de 1995. Em 1994 e 1995, muitas inflorescências não completaram o desenvolvimento em virtude da estiagem ocorrida nos meses de abril a agosto (Figura 1). O período de maior concentração de flores em antese foi verificado entre meados de agosto e meados de setembro, à exceção do ano de 1995, quando houve maior concentração no período de 9 a 23 de agosto (Figura 2).

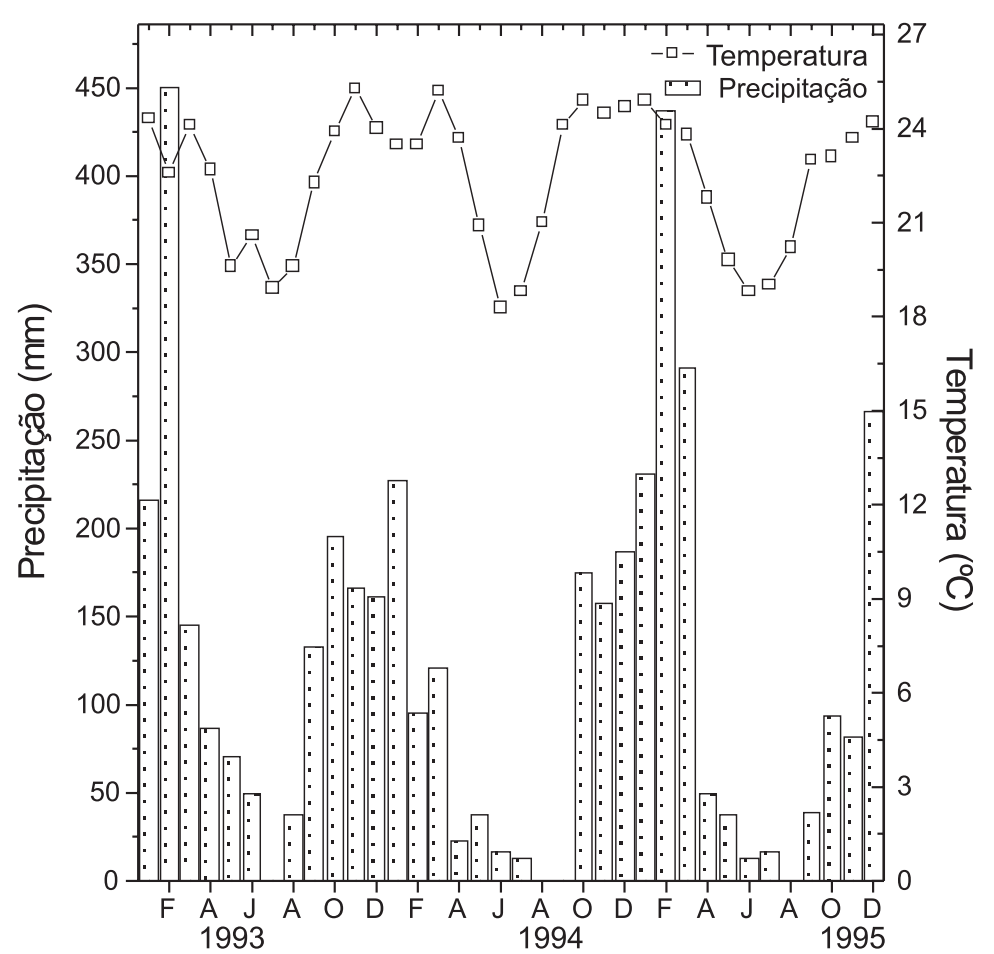

FIGURA 1- Dados de temperatura média e precipitação anual do município de Jaboticabal-SP, nos anos de 1993 a 1995. Fonte: Setor de Climatologia da FCAV-UNESP

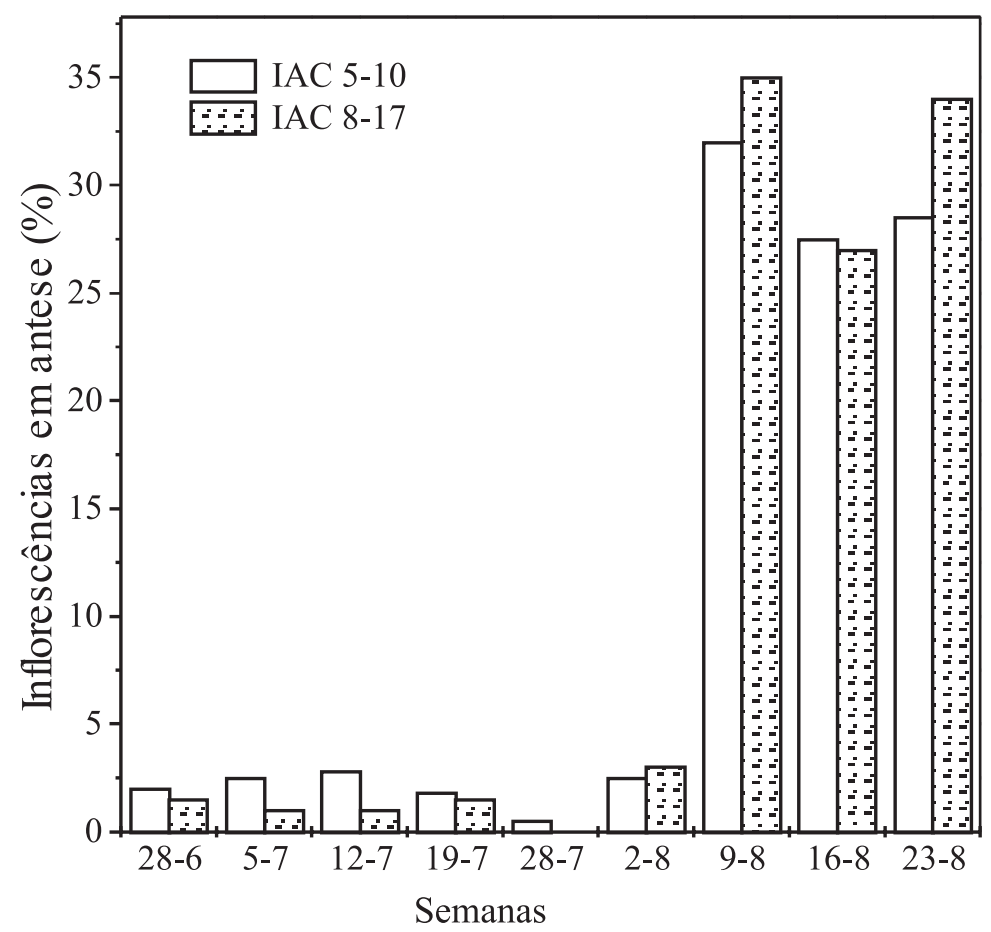

FIGURA 2 - Época de abertura de flores em nogueiras macadâmia das cultivares IAC 5-10 e IAC 8-17. FCAV-UNESP, 1995.

Esses resultados estão de acordo com os períodos observados por Stephenson \& Gallagher (1986), para as condições da Austrália. Verificou-se, também, que o período de início de intumescimento da gema floral coincidiu com a queda de temperatura noturna para as condições de Jaboticabal.

Observou-se que não existe sincronismo de floração num mesmo ramo nem num mesmo nó, pois tanto pode haver lançamentos simultâneos numa mesma axila ou nó, como tais lançamentos podem ser seqüenciais.

A análise de variância do período de crescimento da inflorescência até a antese não detectou diferença significativa entre cultivares com relação ao número de dias e somatório de graus-dia (GD); entretanto, houve diferença significativa, para ambos os parâmetros, 
entre anos e na interação cultivares x anos.

Na Figura 3, observa-se que, em 1994, as inflorescências da cv. IAC 5-10 levaram mais dias para alcançar a antese que as inflorescências da cv. IAC 8-17, não havendo, entretanto, diferença significativa entre as cultivares, em 1995. O período de crescimento das inflorescências de ambas as cultivares, em 1994, foi mais prolongado que em 1995.

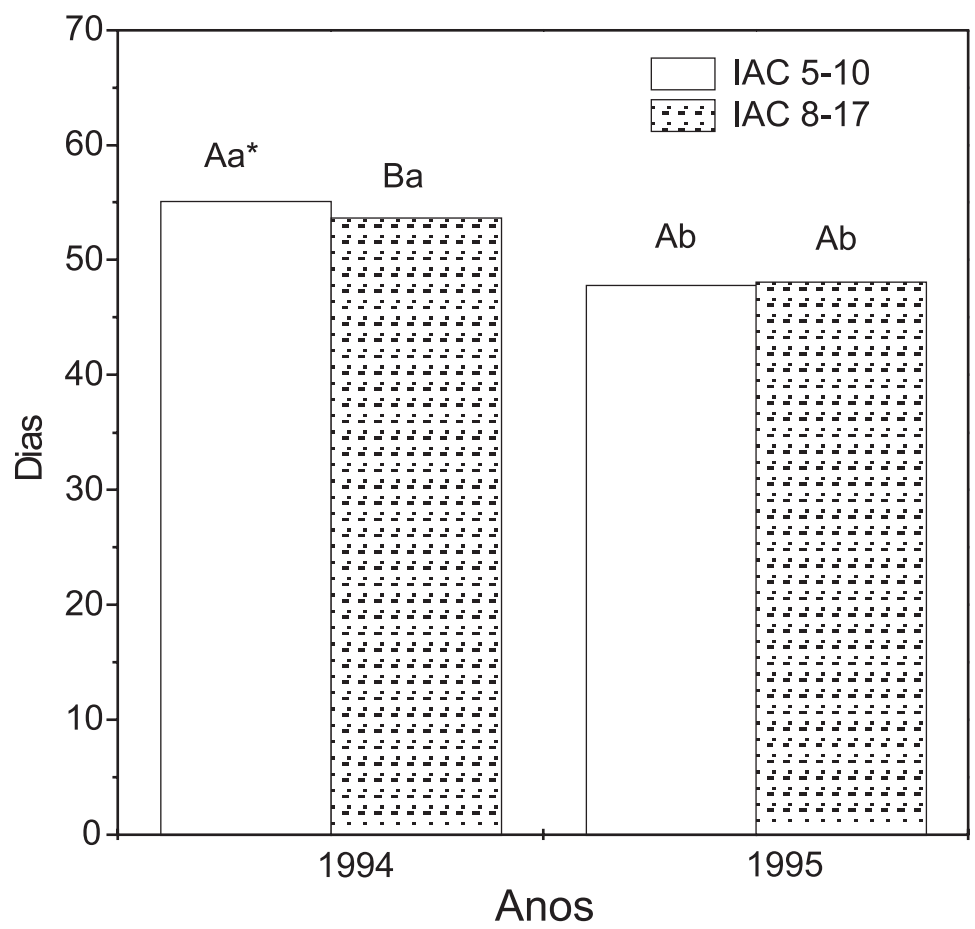

*Letras maiúsculas diferentes em um mesmo ano representam diferenças significativas $(\mathrm{P}<0,05)$ entre cultivares, dentro do mesmo ano; letras minúsculas diferentes representam diferenças significativas $(\mathrm{P}<0,01)$ entre as mesmas cultivares, em anos distintos.

FIGURA 3 - Período (dias) entre início de crescimento e antese de inflorescências em nogueiras macadâmia das cultivares IAC 5-10 e IAC 8-17, em 1994 e 1995. FCAV-UNESP.

Os valores médios de números de dias ocorridos na fase de crescimento da inflorescência das cultivares IAC 5-10 e IAC 8-17, em 1994 e 1995, nas condições de Jaboticabal, são menores que a média encontrada por Moncur et al. (1985), os quais relatam valores médios de 62 dias com extremos de 54 a 90 dias, para cultivares havaianas em diversos locais da Austrália. O período de 90 dias foi encontrado em nogueiras macadâmia cultivadas no local de maior altitude.

Quando mensurado em graus-dia, o período de crescimento da inflorescência foi diferente entre cultivares, em 1994, mas não em 1995 (Figura 4). Ambas as cultivares apresentaram maior somatório de grausdia para o crescimento das inflorescências em 1995, diferindo significativamente de 1994.

Considerando-se que o somatório de graus-dia representa as diferenças de temperatura média diária acima da temperatura-base da macadâmia $\left(12,8^{\circ} \mathrm{C}\right)$ e que, em 1994, as temperaturas médias foram relativamente mais baixas que em 1995, depreende-se, desses resultados, que o crescimento da inflorescência pode ter sido afetado pelas baixas temperaturas, levando mais tempo para alcançar a fase de antese.

A inflorescência (raque) e flor + pedicelo apresentaram crescimento de tendência sigmoidal simples, caracterizado por três fases distintas: uma inicial ou exponencial, na qual o crescimento é relativamente lento; outra intermediária, em que o crescimento é acelerado e praticamente linear, e outra final, onde ocorre estabilização (Figura 5).

No caso da inflorescência, houve um exponencial até o $10^{\circ}$ dia e um período de crescimento linear entre o $10^{\circ}$ e $31^{\circ}$ dia, ocorrendo, a partir deste, a estabilização. Moncur et al. (1985) referem-se à fase de crescimento exponencial e linear como fase de alongamento.

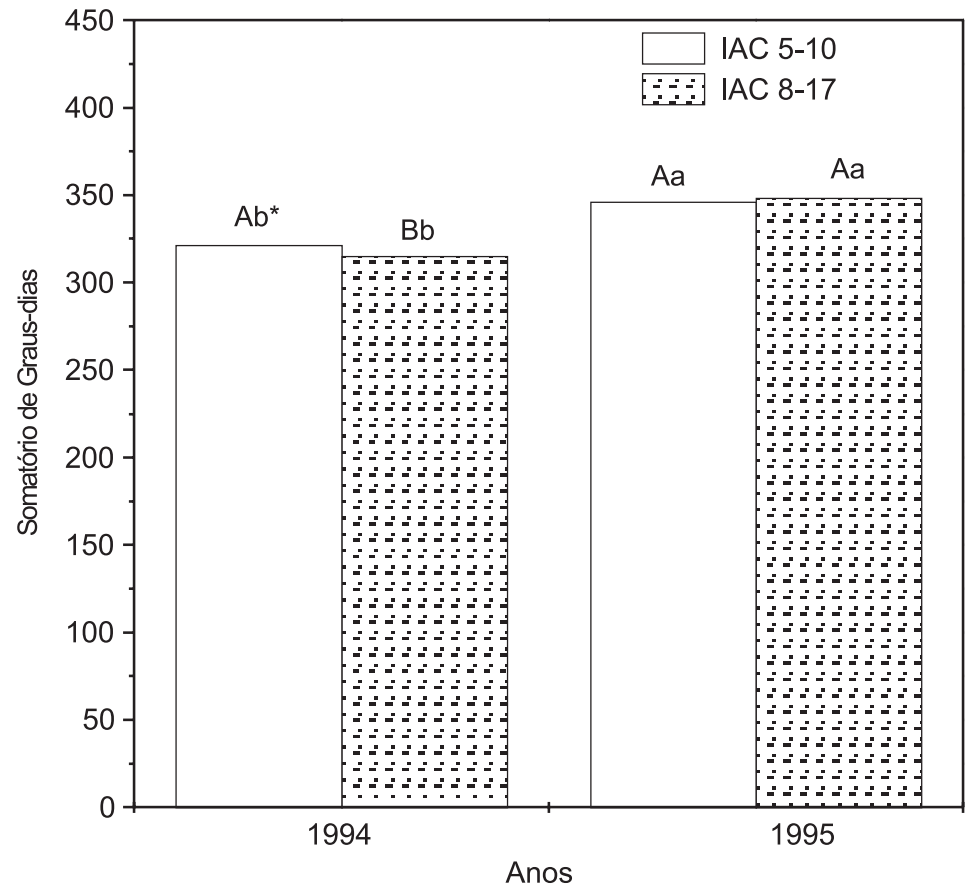

* Letras maiúsculas diferentes em um mesmo ano representam diferenças significativas $(P<0,05)$ entre cultivares, dentro do mesmo ano; letras minúsculas diferentes representam diferenças significativas $(\mathrm{P}<$ $0,01)$ entre as mesmas cultivares, em anos distintos.

FIGURA 4 - Período (Somatório de Graus-dia) entre início de crescimento da inflorescência e antese em nogueiras macadâmia das cultivares IAC 5-10 e IAC 8-17, em 1994 e 1995. FCAV-UNESP.

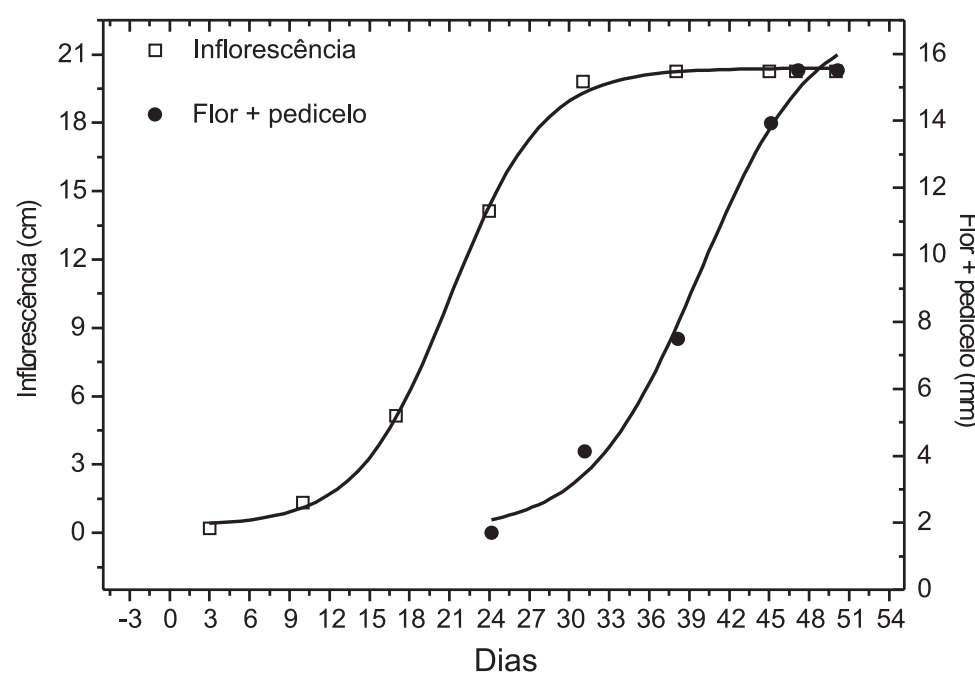

FIGURA 5-Desenvolvimento da inflorescência e da flor + pedicelo de nogueiras macadâmia cultivar IAC 8-17 FCAV-UNESP, 1995.

A flor, aos 24 dias, apresentou um comprimento médio em torno de $1,5 \mathrm{~mm}$, apresentando um crescimento linear do $31^{\circ}$ dia (quando a raque já estava no período de estabilização) até o $45^{\circ}$ dia, quando ocorreu a antese das primeiras flores.

Moncur et al. (1985) observaram que o alongamento dos racemos começou após a temperatura mínima ter aumentado com a ocorrência de chuvas. O alongamento começou mais cedo nos locais mais frios, sugerindo possível requerimento de frio para o desenvolvimento floral. Segundo Moncur et al. (1985), o crescimento do racemo pode ter influência na produção potencial através de um observado decréscimo do número de flores a altas temperaturas para a cv. 246.

De acordo com Leopold \& Kriedemann (1964), para células ou órgãos individuais, o crescimento é potencialmente ilimitado e começa como um padrão exponencial. Entretanto, interações mútuas dentro do indivíduo impõem limitações sobre o crescimento, e a atual curva tende 
a uma maneira sigmoidal. De modo geral, o crescimento de qualquer organismo inclui uma fase exponencial.

\section{CONCLUSÕES}

De acordo com os resultados obtidos, concluiu-se que, nas condições de Jaboticabal, o florescimento da nogueira macadâmia ocorreu entre meados de junho e meados de setembro e que as cultivares apresentaram variação, de um ano para outro, no período ocorrido entre o início de crescimento da inflorescência e a antese

\section{REFERÊNCIAS BIBLIOGRÁFICAS}

ALLAN, P. The future for macadamia nuts. Citrus Grower and Subtropical Fruit Journal, Joanesburg, p. 9-12, 1972.

BITTENBENDER, H. C., McGREGOR, A. Macadamia around the word: situation and perspective. Honolulu, University of Hawaii, p. 294301,1991 .

LEOPOLD, A. C., KRIEDEMANN, P. E. Plant growth and development. Macgraw Hill Book Company, New York 545p. 1964.
MEYER, B. S., ANDERSON, D. B., BOHNING R. H. Introdução a fisiologia vegetal. Fundação Calouste Gulbeukian, Lisboa, 1965, 564p.

MONCUR, M. W., STEPHENSON, R. A., TROUCHOULIAS, T. Floral developmednt of Macadâmia integrifolia Maiden \& Betche under Australian conditions. Scientiae Horticulturae n. 27 p. 87-96, 1985.

NAGAO, M. A., KOBAYASHI, K. D., SAKAI, W. S. Flowering, nut set and premature nut drop of macadâmia, Hawaii Macadâmia Nut Assc. 28 th Annual. Proccedings. p. 54, 1988.

SACRAMENTO, C. K. A macadamicultura no Brasil In: SAO JOSE, A. R. (ed) Macadâmia: tecnologia de produção e comercialização. Vitória da Conquista-Ba, DFZ-UESB, p. 192-197, 1991.

SEQUEIRA, M. A. M., ASTE, V. A. El cultivo de la macadâmia en Costa Rica. Centro Agrícola Cantonal de Turrialba, CACTU, Turrialba, Costa Rica, 1984, 28p.

STEPHENSON, R. A., GALLAGHER, E. C. Effects of night temperature on floral initiation and raceme development in macadâmia. Scientia Horticulturae, 30(3): 213-218, 1986.

STEPHENSON, R.A. Climate adaptation of macadamia. Australian Macadamia Society News Bulletin, v.20, n.2, p. 28-34, 1993. 